\title{
Trained Weakly-electric Fishes \\ Pollimyrus isidori and Gnathonemus petersii (Mormyridae, Teleostei) Discriminate between Waveforms of Electric Pulse Discharges
}

\section{Christian Graff \& Bernd Kramer}

Graff, C. \& Kramer, B. 1992: Trained weakly-electric fishes Pollimyrus isidori and Gnathonemus petersii (Mormyridae, Teleostei) discriminate between waveforms of electric pulse discharges. Ethology $90,279-292$.

\begin{abstract}
Fish of the family Mormyridae emit weak, pulse-like electric organ discharges (EODs). The discharge rhythm is variable, but the waveform of the EOD is constant for each fish, with species- and individual characteristics. The ability of Pollimyrus isidori and Gnatbonemus petersii (Mormyridae) to discriminate between different EOD waveforms was tested using a differential conditioning procedure.

Fish were first trained to respond to a reference signal in swimming to a dish to receive a bloodworm (food reward). The reference signal consisted of a $10-\mathrm{Hz}$ train of the digitally recorded EOD of a conspecific. Second, an alternative signal $(10-\mathrm{Hz}$ train of a different EOD, either from another species, or from a conspecific of the other sex) was associated with air bubbles as punishment. The two signals were played at successive trials in random order. On each trial the latency was measured between the onset of the signal and the response.

7 out of the $8 P$. isidori tested and both of the two G. petersii tested associated the reference EOD with food. Among these, five $P$. isidori and two $G$. petersii responded differentially $(\mathrm{p}<0.01)$ to EODs of different species. $P$. isidori similarly discriminated between conspecific EODs of different sexes. The quantity of different alternative EODs which could be tested was limited when fish eventually habituated to the punishment.

Even when the amplitude of the EODs was randomly changed at each trial, two out of two $G$. petersii differentiated between EODs of the two species, and three out of three $P$. isidori tested differentiated between EODs within their own species.

Response latencies to the rewarded signal during the basic training and during discrimination (when it had to be distinguished from the $\mathrm{S}-$ ) were similar. G. petersii showed differential responses for $\mathrm{S}+$ and $\mathrm{S}-$ also in the rhythm of discharge exhibited during playback, after five EOD pulses for one fish, and after a single pulse for the other.

Mormyrids may therefore distinguish between conspecifics and members of other species, and even between individual conspecifics, by their EOD waveform.
\end{abstract}

Corresponding author: Christian GRAFF, Laboratoire de Biologie du Comportement, Département de Psychologie, UFR SHS, Université des Sciences Sociales, 47X, F-38040 Grenoble Cedex. 


\section{Introduction}

Weak electric discharges of mormyrid and gymnotiform fishes were unknown before the 1950's because they are imperceptible to human senses. Electronical measurement devices provide us now with pictures and parameters of these signals with an accuracy which may be beyond the fish's own sensitivity. Mormyrid electric organ discharges (EODs) consist of short pulses separated by highly variable time intervals (in the range of 10 to $1000 \mathrm{~ms}$ ). The shape of the pulse, or EOD wave form is constant for a given individual. It varies from species to species (LisSMANN 1958; Hopkins 1981), as it does in gymnotiforms (LISSMANN 1961; Kramer et al. 1981). In Brienomyrus brachyistius (Mormyridae), differences in EOD wave form suggested the existence of three species for one morphotype (Hopkins 1981).

EOD discrimination was investigated in gymnotiforms with wave EOD (Hopkins 1972), then with pulse EOD (Heiligenberg \& Altes 1978). Differential responses of fishes to digitally synthesized male and female discharges emphasize the importance of the EOD waveform in sex recognition in a gymnotiform with a wave discharge (Kramer \& Zupanc 1986; Kramer \& OTTO 1988). In mormyrids, pulse EOD discrimination has been reported in Brienomyrus brachyistius "long triphasic" only (HOPKINS \& BAss 1981), using spontaneous responses. We focus in this study on less "exotic" mormyrid species which display much shorter discharges than the investigated B. brachyistius "long triphasic": Pollimyrus isidori, the only mormyrid breeding in captivity (Kirschbaum 1987; CraWFord et al. 1986; BratTon \& Kramer 1989); and Gnathonemus petersii, the well-known "elephant-nose fish". Kramer \& WeSTBY (1985) found no difference of the EOD waveform between the two sexes of G. petersii, although these results have been subject to controversy (LANDSMANN \& Moller 1987, 1988). In contrast, in P. isidori, Westby \& Kirschbaum (1982) proposed a sex recognition based on EOD discrimination, as males of this species often have a first positive phase of the EOD, P1, smaller than the last one P2 (that is, low P1/P2 ratio), whereas in females P1 is most often greater than P2 (Fig. 2 and Table 1 give a description of EOD pulses). BRATTON \& Kramer (1988) confirmed this difference in the waveform, as well as a lower peak frequency in the power spectrum of males compared with females (this latter difference was not significant). However, because of the strong overlap of these characters between the sexes, these authors consider that most individuals cannot be reliably sexed on the basis of their EOD waveform. They also state that the EOD waveform changes with water conductivity.

The complex electroreceptor situation in the mormyrid skin (reviews BENNETT 1971; BELL 1986, $1990 \mathrm{a}, \mathrm{b}, \mathrm{c}$ ) and the stability of the EOD waveform, consistent over days or weeks (BratTon \& Kramer 1988), led us to test the hypothesis of EOD waveform discrimination. Stable differences among the waveforms of individual Pollimyrus isidori make possible the recognition of individuals on the basis of waveform. On the other hand, the EOD pulse of $P$. isidori is very short in comparison with other mormyrids: it lasts only $100-250 \mu$ s, i.e. $1 / 10$ to $1 / 4$ of the duration of a nerve action potential. If the EOD 
waveform does function as a communication signal, the physiological mechanisms responsible for the analysis of such a short stimulus would deserve special attention.

The possibility of EOD discrimination by $P$. isidori and $G$. petersii is tested here by play-back experiments using the conditioned discrimination procedure. Weakly-electric fish often spontaneously swim towards stimulus electrodes (KRAMER 1979; SCHLUGER \& HopkINS 1987). Yet the response depends in part on the sequence of pulse intervals (Kramer 1979; Teyssedre \& SERrier 1986), and it is subjected to habituation. Therefore, in this study the fish was rewarded in order to maintain a measurable response to play-back of a given EOD waveform. When the same response was made to an alternative EOD of different waveform, punishment followed. Similar "go / no go" procedures had been used in trained Eigenmannia (Gymnotiformes; Kramer \& ZuPANC 1986).

\section{Methods}

\section{Animals and Animal Care}

The Pollimyrus isidori, named $\mathrm{Pi}-1, \mathrm{Pi}-2, \mathrm{Pi}-3, \ldots, \mathrm{Pi}-12$, originated from Ikea (Nigeria) according to the tropical fish dealer. They had lived in aquaria for over three years, and measured $60-80 \mathrm{~mm}$ (standard length), corresponding to adult size. The Gnatbonemus petersii named Gp-1 and Gp-2 were caught in Zaire according to the dealer and had probably lived in captivity for less than three months. They measured 85 and $95 \mathrm{~mm}$ and were therefore juveniles. Fish Pi-4 had been isolated about seven months before the beginning of the training; the other fish were housed in groups of 5 to 15 in 150-300-1 tanks. They were fed frozen bloodworms (chironomid larvae) five times per week. The artificially controlled L : D period was $12: 12 \mathrm{~h}$.

For tests, each fish was isolated in a $100-1$ experimental tank (temperature of $26-28^{\circ} \mathrm{C}$; conductivity of $48-52 \mu \mathrm{S} / \mathrm{cm}$ ) with some "Java moss" (Vesicularia dubyana, Hypnobriales). Light came from a $20-\mathrm{W}$ fluorescent tube $(30 \mathrm{~cm}$ distance), or a $40-\mathrm{W}$ incandescent lamp (10 cm distance). Vision outside the tank was restricted to the front side. A porous ceramic tube (diameter $42-49 \mathrm{~mm}$, length $166 \mathrm{~mm}$ ) placed in the middle of the tank was accepted by the fish as a hiding place. Food was presented in a mini glass petri-dish (diameter $55 \mathrm{~mm}$, height $10 \mathrm{~mm}$ ) placed in a corner. The set-up is presented in Fig. 1.

\section{Conditioning Procedures}

\section{Basic Training}

Before training, the fish was kept isolated in the experimental tank for more than a week. After 2-4 $\mathrm{d}$ without food, the reference signal $\mathrm{S}+$ was presented during the dark period (mormyrids are less active during the day). The fish spontaneously approached the active electrodes and this spontaneous reaction was reinforced and progressively directed towards finding food in the dish at this moment. When a fish did not spontaneously respond to the signal, the signal was switched on when the fish spontaneously started eating. When the fish was too shy and did not find the reward, the petri dish was placed nearer to the hiding place, and then progressively moved back to the corner. The fish was fed only during stimulation, and eventually accepted food also during the day. This part of the training lasted from 1 to $10 \mathrm{~d}$.

The response latency was measured in s between the onset of the signal and the moment the fish put its snout inside the petri dish.

The positively reinforced stimulus $(\mathrm{S}+$ ) was turned off as soon as the reward was delivered to the fish. The reward consisted of one or several bloodworms injected into the petri dish using a syringe and a tube. Any remaining food was removed with a pipette, after the fish had eaten. 


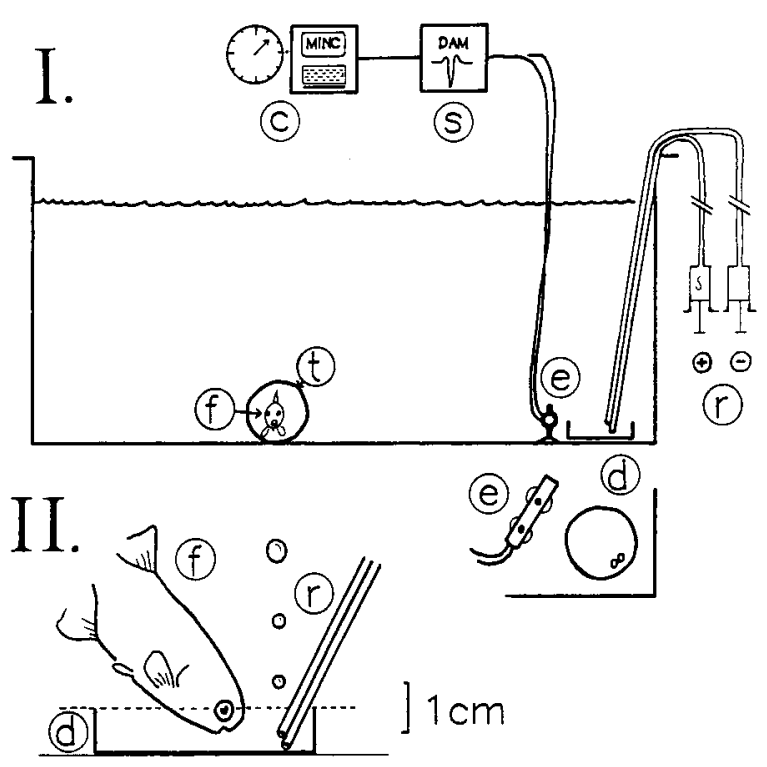

Fig. 1: Schematic diagram of the experimental tank. I. overview. II. close-up, response of the fish. c. computer with built-in stopwatch; d. mini petri-dish; e. stimulation electrodes; $f$. fish; $t$. ceramic tube; s. signal generator; r. reinforcement set-up. When the fish's snout crossed the rim of the petridish, it was either rewarded with a blood worm or punished with air bubbles ejected through the reinforcement set-up

\section{Testing Trials}

The presentation of an EOD stimulus, measurement of response latency, and reinforcement, constituted a "trial". In "positive trials", as described above, the EOD stimulus was the reference signal $\mathrm{S}+$, and the (positive) reinforcement was food.

For assessing the basic training, positive trials were compared to "blank trials". In blank trials, a key was pressed but no stimulus given. A fictitious "latency" was measured to the fish's next "response". (Most fish came quite often to check the dish when the experimenter was in the room.) There was no reward in blank trials. EODs.

The fish was further trained and tested for its capacity of discriminating two different synthetic

For both conditioning and testing the fish for discrimination, positive trials were followed by and compared to "negative trials".

In "negative trials", the presented stimulus $\mathrm{S}$ - was an alternative synthetic EOD that was used for play-back, but reward was replaced by punishment. Punishment consisted of air bubbles, delivered when the fish inspected the dish for food, chasing the fish away. Air bubbles were injected with a second syringe-tube arrangement. When the fish had associated the alternative signal with punishment, it took longer to respond to the stimulus, or did not respond at all. Some fish habituated to the air bubbles, and tended to respond faster and faster even at alternative trials. Punishment was then intensified by simultaneously frightening the fish by knocking on the aquarium wall or the support, or by moving a plastic rod in the water. trial.

Immediately after either reinforcement, the syringe-tube arrangement was prepared for the next

Trials were scheduled every $2 \frac{1}{2}$ min but when the fish was swimming about, stimulus onset was delayed until the fish had gone back to its ceramic tube, with the head oriented towards the opening. A delay in one trial normally did not delay the next one, although a minimum of $1 / 2$ min separated two adjacent trials. The maximum duration of signal presentation was $1 \mathrm{~min}\left(1 \frac{1 / 2}{2}\right.$ for some individuals).

\section{Discrimination "Sessions" and "Series"}

When the fish seemed to have learned first the basic training, then the discrimination, the trials were organized in formal "sessions" of trials. 
Test sessions were conducted during the day, 4-6 d a week, once or twice daily, with a $1 \frac{1 / 2}{2} \mathrm{~h}$ minimum between sessions of trials. Each session lasted $1 \mathrm{~h}$, and consisted of 20 trials following a preparation of 5 "introductory" trials.

The first 5 introductory trials of a session consisted of: two positive trials, followed by one negative trial, followed by two positive ones. The sequence of the 20 other trials was random (coin tossed) except for two restrictions: 1 . a maximum of three positive or three negative trials was allowed in a row; 2. a total of 10 positive and of 10 negative trials occurred in each session of trials.

In basic training sessions, the format was the same, with blank trials (without stimulus) instead of negative trials (with $\mathrm{S}-$ ).

Sessions were repeated in series until the results differed significantly for the $\mathrm{S}+$ and $\mathrm{S}-$. This discrimination training procedure was adequate for most, but not for all fish, which sometimes remained in the ceramic tube after a punishment. When fish did not perform the task in two or three sessions of discrimination trials, a step back to basic training (without $\mathrm{S}$ - and negative reinforcement) was sometimes helpful.

A potential influence on the fish from handling the reinforcing equipment was controlled against the $\mathrm{S}+$ and $\mathrm{S}-$ themselves. The experimental series were completed with 5 final sessions (of 20 discrimination trials each). Every 5 th trial of these final sessions, the reinforcing apparatus was not handled at all, and two "nonreinforced" trials of either type were thus recorded. This provided a total of 10 nonreinforced positive and 10 nonreinforced negative trials at the end of each series.

\section{Synthesized EODs Used for Play-back}

\section{Apparatus of Signal Generation}

The stimulus signals were presented via an electrode dipole next to the petri-dish feeding station. The carbon rod poles ( $5 \mathrm{~mm}$ diameter, $10 \mathrm{~mm}$ long) were oriented vertically, and separated by $30 \mathrm{~mm}$. The carbon rods were supported by a horizontal plexiglass tube $(10 \mathrm{~mm}$ diameter, $120 \mathrm{~mm}$ long), $40 \mathrm{~mm}$ above the bottom of the tank, attached to suction caps.

The stimulus signals were generated by a digital-to-analogue converter with memory, controlled by its own microprocessor (KRAMER \& WEYMANN 1987) that was instructed by a host computer (Minc 23, Digital Equipment Co). All synthetic EODs were presented at $10 \mathrm{~Hz}$ repetition rate. The pulses were natural EODs from BRATTON \& KRAMER's (1988) study, recorded and digitally stored at $2-\mathrm{MHz}$ resolution. These (analogue-to-digital) data were first scaled and normalized by a computer program according to KRAMER \& WEYMANN (1987), and then played back at $500-\mathrm{kHz}$ resolution.

The peak-to-peak amplitude of the first $\mathrm{S}+$, the synthesized signal of a Pollimyrus normal male, named PNM, was $7.8 \mathrm{~V}$ at the stimulator output. This amplitude matched the amplitude of a fish's EOD. The synthesized EOD emitted by the dipole and recorded from the ceramic tube hiding place, had the same amplitude as the EOD emitted by fish in this tube and recorded from the dipole's place. This recorded amplitude was in the range of 4 to $15 \mathrm{mV} / \mathrm{cm}$.

\section{Waveform and Amplitude of the Synthesized EODs}

The different synthetic EODs used in this study are presented in Fig. 2, and detailed in Table 1.

For fish Pi-2 only, the amplitude of the EOD of the alternative signal was that of the reference signal EOD.

For all other fish, the peak-to-peak amplitude (voltage) of the alternative signal (S-) was adjusted to match its total energy with that of the reference EOD $(\mathrm{S}+)$.

The energy is the integral over time of: $I(t) * U(t)$, where: $I=$ current; $t=$ time; $U=$ voltage. With a constant resistance $R$ between electrodes, $I=U / R$, hence the energy is the integral of: $U^{2}(t) / R$. For EOD pulses digitally sampled at constant rate, (and without direct current component), the estimated total energy content $E$ is proportional to the squared voltage amplitudes $U_{i}$, summed over the $\mathrm{n}$ sampling points, according to the formula:

$\mathrm{E}=\mathrm{k} * \sum_{\mathrm{i}=1}^{\mathrm{n}}\left(\mathrm{U}_{\mathrm{i}}\right)^{2}$ with $\mathrm{k}$ a constant value (see GREENBERG 1975). 

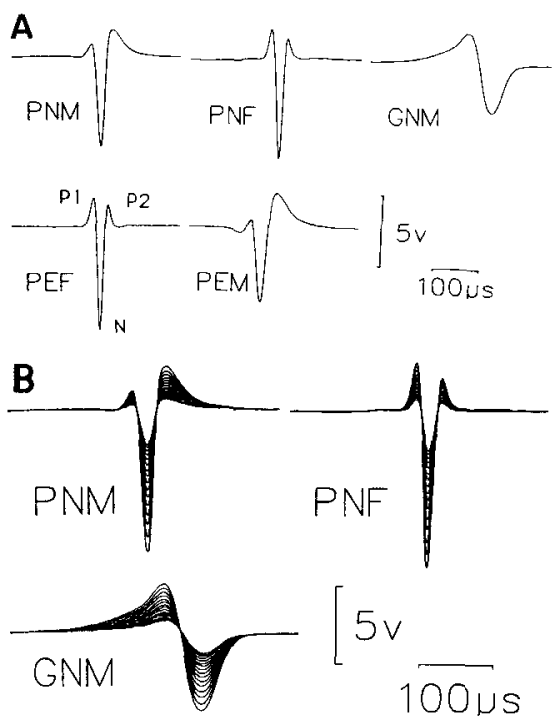

Fig. 2: Synthetic EODs used for play-back. Oscillograms of EOD waveforms played back to the fish. Head-positive polarity is upwards. A. EOD waveforms normalized for equal energy contents. B. superimposed EOD waveforms at 16 different amplitude levels. Smallest amplitude is half, largest twice the normalized amplitude. GNM: Gnathonemus petersii. PNM: Pollimyrus isidori, "normal" male. PNF: Pollimyrus isidori, "normal" female. PEM: Pollimyrus isidori, other male. PEF: Pollimyrus isidori, other female. See Table 1 for details. All EODs played in trains, at 10 per s. PNM or PNF were used as reference signal for $P$. isidori, and GNM for G. petersii. All EODs served as alternative signals. The negative phase $\mathrm{N}$ and the two positive phases P1 and P2 are labelled for PEF as examples

The reference signal $\mathrm{S}+$ of the basic training trials was kept as the positively reinforced signal during the sessions of discrimination trials. The reference EOD played back to G. petersii was designated GNM. It had been recorded from another G. petersii. For $P$. isidori, the reference signals (PNM or PNF) were from a male and a female $P$. isidori respectively, whose sex had been determined during previous spawnings. All parameters of the pulses (that is, P1/P2 ratio, N-phase duration, and peak power frequency; see BRATTON \& KRAMER 1988) were within one standard deviation of the population mean (for this sex) (Table 1).

The alternative signals, $\mathrm{S}-$, were either synthesized EODs of another species, or a synthesized EOD of the same species but of the opposite (to $\mathrm{S}+$ ) sex for $P$ isidori. $\mathrm{S}+$ and $\mathrm{S}$ - were played back with identical energy contents. In the last series of experiments, however, the amplitude was randomly changed at each trial.

Table 1: Features of the discriminated EOD waveforms. Stimulus EODs are compared with $\bar{x} \pm S D$ from larger samples (data from KRAMER \& WESTBY 1985 and BRATTON \& KRAMER 1988). Data on the stimulus EODs as output by the DAM signal generator. Frequency of peak amplitude computed by fast Fourier transform of the source signals. $\mathrm{P} 1, \mathrm{P} 2$ and $\mathrm{N}$ phases are presented in Fig. 2. P1/P2 ratio is defined as the amplitude ratio of the first head-positive phase over the second. $\mathrm{N}$ phase duration is the duration of the head-negative main phase (between zero-crossings).

Note that the ranges of EOD features overlap for male and female $P$. isidori, but they are far beyond the corresponding ranges in $G$. petersii. The second positive phase is almost non-existing in $G$. petersii

\begin{tabular}{|c|c|c|c|c|c|c|c|c|c|}
\hline \multirow[b]{2}{*}{ EOD name: } & \multicolumn{3}{|c|}{ P. isidori female } & \multicolumn{4}{|c|}{ P. isidori male } & \multicolumn{2}{|c|}{ G. petersii } \\
\hline & $\begin{array}{l}x \pm S D \\
(n=14)\end{array}$ & PNF & PEF & & $=10)$ & PNM & PEM & $(\mathrm{n}=8)$ & GNM \\
\hline $\mathrm{P} 1 / \mathrm{P} 2$ ratio & $1.17 \pm 0.82$ & 1.48 & 1.31 & $>0.4$ & $.49 \pm 0.26$ & 0.47 & 0.23 & $>20.0$ & 44 \\
\hline $\begin{array}{l}\text { N-phase } \\
\text { duration }[\mu \mathrm{s}]\end{array}$ & $25.8 \pm 3.9$ & 22.3 & 20.1 & $<28.6$ & $.6 \pm 5.3$ & 28.1 & 32.4 & $153 \pm 25$ & 11 \\
\hline $\begin{array}{l}\text { Frequency of peak } \\
\text { amplitude }(\mathrm{KHz})\end{array}$ & $16.4 \pm 4.4$ & 20.1 & 22.3 & $>13.4$ & $.4 \pm 4.0$ & 12.2 & 8.2 & - & 4.3 \\
\hline
\end{tabular}




\section{Recording of Performance}

The discrimination criterion was based on the latency from the onset of the signal to the fish's putting its snout into the petri dish. A Mann-Whitney U-test (SIEGEL 1956) was conducted on the 20 trials of each session. The 20 nonreinforced trials included in the 5 final sessions were tested in the same way. A $1 \%$ level of significance (one-tailed) was required to assess a response latency to the reference signal $\mathrm{S}+$ shorter than to the alternative signal $\mathrm{S}-$.

Pollimyrus isidori took 5-15 sessions of trials for the basic training. 8 of 12 tested fish learned without problem, one failed to do so after 22 sessions of trials, and three would not eat in the experimental tank. Both G. petersii learned within a series of three sessions of trials.

As an example, the performances of fish $\mathrm{Pi}-3$ and $\mathrm{Pi}-4$ are presented in Fig. 3. Nonreinforced trials were used as follows. First the 10 nonreinforced positive trials included in five sessions of experiments were tested against the 10 nonreinforced negative trials at the $1 \%$ level, as above for
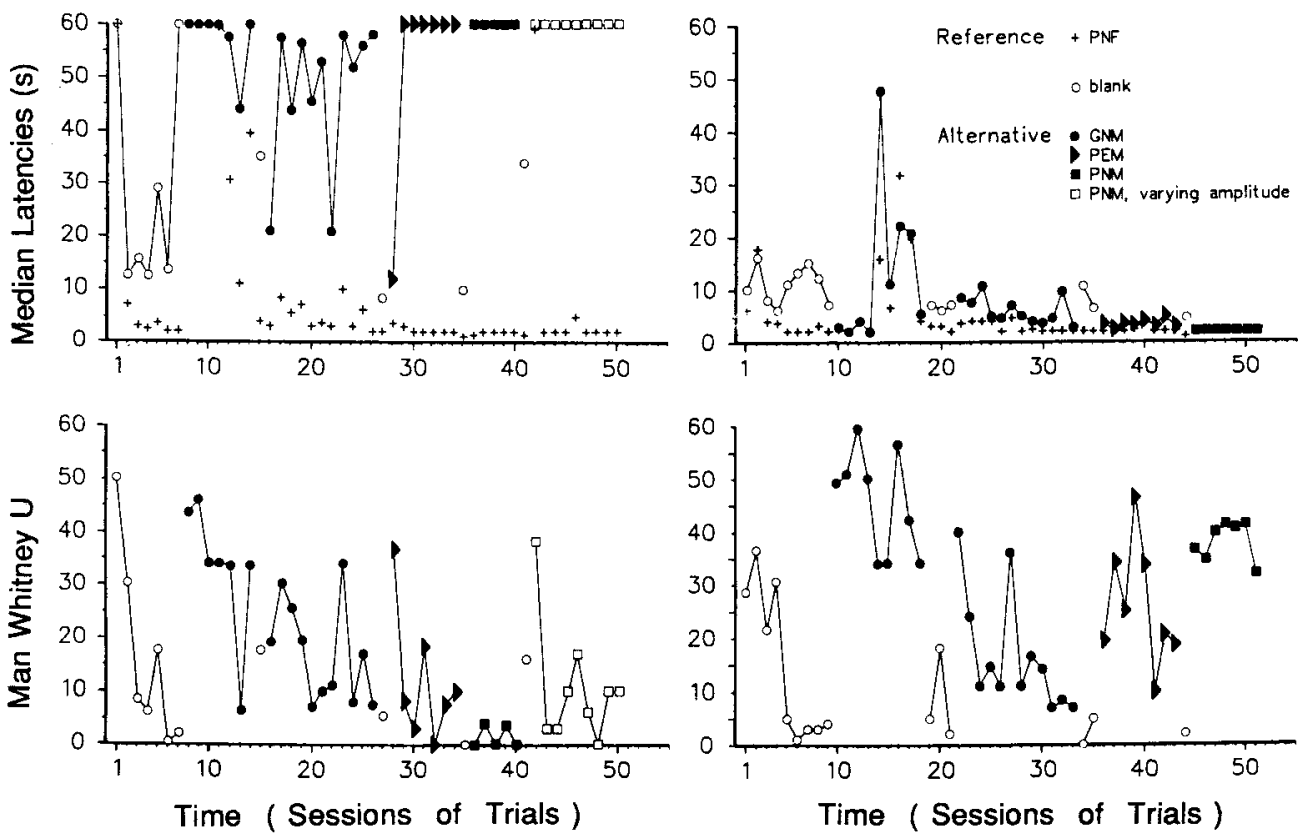

Fig. 3: Performance of two fish at basic training and discrimination experiments: fish Pi-3 (right) and Pi-4 (left). Abscissa: Sessions of trials in chronological order. Each session includes 10 trials using the positively reinforced reference signal $(S+)$ and 10 trials using an alternative, negatively reinforced signal $(\mathrm{S}-)$ or a blank.

Ordinate, top graphs: median latencies of response $(n=10$ trials per session), $(+)$ to the $S+$, and $(a$ different symbol, see below) to the $\mathrm{S}-$ or the blank. Both, $\mathrm{S}+$ and $\mathrm{S}-$, response latencies of a given session are at the same abscissa. A line joins $S-$ symbols of successive sessions of the same experimental series.

Ordinate, bottom graphs: $\mathrm{U}$-value of Mann-Whitney test for difference between latencies for $\mathrm{S}+$ and $\mathrm{S}-$. If $\mathrm{U}<32$, then $\mathrm{p}<.10$; and if $\mathrm{U}<19$, then $\mathrm{p}<0.01$. + , reference signal, PNF. Open circles, blank, that is fictitious stimulation, used in basic training. Alternative signals $S-$ are: solid circles, GNM; solid triangles, PEM; solid squares, PNM; open squares, PNM with varying amplitude (see Table 1 and Fig. 2).

Fish Pi-4 learned to discriminate the S- from the S+ even at varying amplitudes. Fish Pi-3, on the other hand, finally habituated to the punishment and became indiscriminate after performing quite well in the middle of the test series 
normal testing trials. Second, when there was a significant difference: these 10 nonreinforced positive trials were compared with the 40 normal reinforced positive ones of the same 5 sessions of trials; and the 10 nonreinforced negative were compared with the 40 reinforced negative trials of the same sessions. No difference ever appeared, even at the $10 \%$ significance level. This shows that the fish relied on cues from the signal itself, and not on cues associated with the delivery of reward and punishment. Also the key pressed to deliver either signal, or blank, was the same, the nature of the stimulus being programmed just after the previous trial.

The EOD rhythm of $G$. petersii was recorded on a cassette recorder (CP430, Marantz). EOD intervals were analyzed on "Oscilloscript" film, using an oscilloscope camera (Recordine K-544, Tönnies, Freiburg) at $1 \mathrm{~m} / \mathrm{s}$ film speed past the open shutter. EODs of the tested fish were counted per 100-ms intervals, either between stimulus EODs, or before stimulus onset.

\section{Results}

\section{Discrimination of Synthetic EODs}

The results of discrimination are summarized in Table 2.

\section{Interspecific Discrimination}

In the first experimental series, the alternative signal S- was a train of EOD of the other mormyrid species: G. petersii was tested with PNF, P. isidori with GNM. 5 out of $7 P$. isidori discriminated an EOD of their own species from that

Table 2: General performance of Pollimyrus isidori and Gnathonemus petersii at EOD recognition. Significance level reached at discrimination: $(* *) p<0.01$ at normal trials; $* * * 0.01$ also at control (un-reinforced) trials; $* \mathrm{p}<0.05$ reached only when pooling trials of more than one session of 20 trials; nt: not tested; PEF and PEM, PNF and PNM, and GNM refer to EOD waveforms presented in Table 1 and Fig. 2.

Remark: To be added to Table A: two P. isidori ( $\mathrm{Pi}-7$ and $\mathrm{Pi}-8$ ) completed the basic training successfully but did not differentiate; one (Pi-9) failed the basic training, and two (Pi-10 and Pi-12) would not eat in the experimental tank. For all test fish, reference and alternative signals were normalized according to energy content, but for Pi-2 where PNF and GNM were normalized according to the amplitude

\begin{tabular}{|c|c|c|c|c|c|}
\hline \multirow{2}{*}{$\begin{array}{l}\text { Tested fish } \\
P . \text { isidori } \\
\quad \text { (sex) }\end{array}$} & \multirow{2}{*}{$\begin{array}{c}\text { Reference signal } \\
(\mathrm{S}+) \\
\text { same species } \\
(P . \text { isidori })\end{array}$} & \multicolumn{4}{|c|}{$\begin{array}{c}\text { Alternative signals } \\
\text { (S-) } \\
\text { same species }(P \text {, isidori }\end{array}$} \\
\hline & & (G. petersii) & extreme & normal & $\&$ var. ampl. \\
\hline Pi-1 (M) & PNF & GNM** & PEM $*$ & $\mathrm{nt}$ & $(* *)$ \\
\hline $\operatorname{Pi}-2(\mathrm{~F})$ & PNF & GNM $* \%$ & PEM $^{* *}$ & PNM** & $\mathrm{nt}$ \\
\hline $\mathrm{Pi}-3(\mathrm{~F})$ & PNF & GNM $* *$ & PEM** & PNM** & $* *$ \\
\hline $\mathrm{Pi}-4(\mathrm{~F})$ & PNM & $\mathrm{GNM}^{*}$ & PEF** & $P N F * \%$ & $(* * *)$ \\
\hline $\operatorname{Pi-5}(\mathrm{M})$ & PNM & $\mathrm{GNM}^{* *}$ & $\mathrm{PEF}^{* *}$ & $\mathrm{PNF}^{*}$ & $\mathrm{nt}$ \\
\hline G. petersii & $\begin{array}{l}\text { same species } \\
\text { (G. petersii) }\end{array}$ & $\begin{array}{l}\text { other species } \\
\text { (P. isidori) }\end{array}$ & & / variable & litude \\
\hline Gp-1 & GNM & PNF*: & & $* *$ & \\
\hline $\mathrm{Gp}-2$ & GNM & PNF": & & $\because *$ & \\
\hline
\end{tabular}


of a G. petersii played back at the same rate. Fish Pi-2 was tested with EODs of identical peak-to-peak amplitude and discriminated these. All other fish were tested with synthetic EODs of identical energy content and also discriminated these pulse waveforms.

\section{Intraspecific Discrimination}

In the second experimental series, $P$. isidor $i$ was tested with an alternative signal (PEF or PEM) from a conspecific of the other sex (i.e. different from that of the reference EOD). The alternative synthetic EOD was somewhat "extreme", i.e. had some (putative) sexual characteristic pronounced (Fig. 2).

All five $P$. isidori that discriminated EODs of their own species from those of G. petersii also discriminated between different intraspecific EODs. This discrimination became significant very soon, either at the first or at the second session of discrimination trials. Just as for species discrimination, the difference was also significant in 20 nonreinforced trials.

In the third experimental series, four $P$. isidori were tested with another alternative signal (PNF or PNM) from a conspecific of the opposite sex (compared to that of the reference signal), with all three parameters (P1/P2, peak amplitude frequency, $\mathrm{N}$-phase duration) within normal range.

$\mathrm{Pi}-4$ and $\mathrm{Pi}-5$ showed significant discrimination already after the first session of trials, while the other test fish did not. Pi-7 was not consistent in its performance, and Pi-3 came too fast (see Fig. 3).

\section{Independence of Amplitude}

Three P. isidori and two G. petersii were tested for an amplitude dependence of their discrimination performance. The reference and the alternative signals (PNM or PNF for P. isidori, and PNM for G. petersii) were played back with variable amplitudes. At each trial, an amplitude was randomly chosen among 16 values ranging between one-half and two times the energy-standardized amplitude. In this experimental series, the same amplitude of a given EOD was not used more than twice during the same session of 20 trials. All fish tested discriminated successfully the $S+$ from the $S-$ regardless of the amplitude variation.

Fish Pi-4 discriminated between two "normal" conspecific EODs regardless of the amplitude after two sessions of discrimination trials. Control trials were also successfully conducted for this task.

Fish Pi-2, after a basic training on reference signal PNF with variable amplitude, succeeded in distinguishing it from another EOD of the same species (PEM) with variable amplitude. It was unfortunately frightened by an accidental knock on the aquarium just when taking a reward, and fled to its hiding place. Although it progressively began to respond again to the reference signal at basic training, it stopped leaving its hiding place as soon as negative trials were reintroduced, even 4 weeks later. Nevertheless, the trials prior to the disturbance showed discrimination at the $1 \%$ significance level but nonreinforced trials could no longer be performed. 
Fish Pi-5 discriminated between "normal" signals of different sexes (PNM and PNF) with variable amplitudes, but its performance varied. In fact, superimposed on its preference for the positively reinforced signal (i.e., its shorter latency to respond) the fish came gradually faster when the signal was "louder", i.e., with higher amplitude. It also did so in basic training with varying amplitude. [Spearman's rank correlation $r_{s}=0.81$ and $r_{s}=0.89$, for $S+$ and $S-$ respectively $(n=60) ; r_{s}=0.62(n=40)$ at basic training; $\mathrm{p} \ll 0.001$ in all cases.]

Both $G$. petersii discriminated between the signals of the two species played back with variable amplitude. Gp-2 did so at the first, and Gp-1 at the second session of trials, then also at nonreinforced trials.

\section{Time Required for Discrimination}

Latencies as measured here give only an upper limit of the time needed by the fish to discriminate the signals. Just like in basic training, the latency also includes: time to react, time for making a decision (hesitation), and locomotion. The time of hesitation was, apparently, responsible for the major part of the variation. The response to the reference signal at the first significant session of discrimination trials was delayed by $6.5 \mathrm{~s}$ compared to the same signal in basic training (median among 7 fish, of median latency per session of trials). This delay decreased with experience, and in the last sessions of discrimination trials, the fish responded to the reference signal as fast as they did in basic training (median difference is $0 \mathrm{~s}$ for both species, see the examples of Fig. 3). The precision for these measurements was $1 \mathrm{~s}$.

A finer estimation of discrimination time was possible using the fish electrical activity, recorded during sessions of discrimination trials (species recognition with varying amplitude, Fig. 4).

$\mathrm{Gp}-2$ increased its discharge rate at the onset of the stimulus. The number of EODs during the $100 \mathrm{~ms}$ interval following the first stimulus pulse is significantly
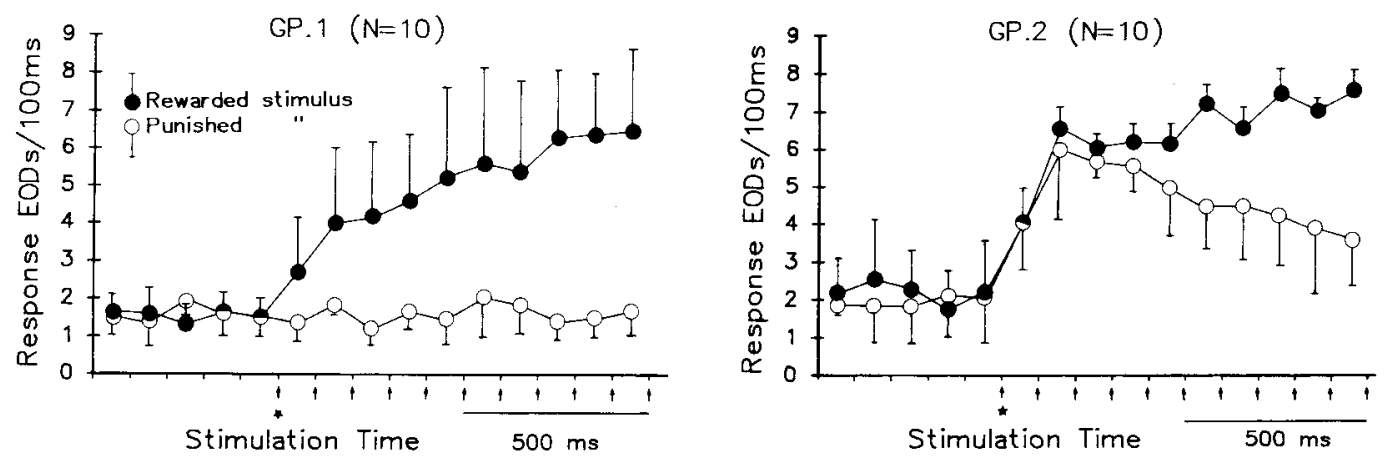

Fig. 4: Electrical response of $G$. petersii $\mathrm{Gp}-1$ (left) and $\mathrm{Gp}-2$ (right) to the stimulus signals. Star: stimulus onset; arrows mark each pulse of the stimulus train. Stimulus pulses are separated by $100-\mathrm{ms}$ intervals. Ordinate: discharge rate, i.e., number of EODs per 100 -ms interval. $\bar{x}$ with SD for 10 trials. Solid circles: response to reference (positive) signal $(S+)$; open circles: response to alternative signal $(\mathrm{S}-)$ 
increased (U-test, $\mathrm{p}<0.01$ ) compared to the preceding $100 \mathrm{~ms}$. The EOD rate decreased again in the case of an alternative (negative) signal, whereas it remained on a high level (during swimming) in response to the reference (positive) signal. The rate difference between positive and negative trials was significant $(p<0.05)$ after the fourth stimulus pulse of the train and highly significant $(p<0.01)$ after the fifth.

Gp-1 did not respond at all to the alternative signal $\left(S_{-}\right)$, but increased its EOD rate significantly $(p<0.05)$ at the first pulse of the positive signal. Its EOD rate in response to the negative signal was significantly different from that to the positive one, after the first stimulus pulse. The difference is highly significant $(p<0.01)$ after the second pulse. The fish therefore recognized a single EOD pulse, in less than $200 \mathrm{~ms}$.

\section{Discussion}

These results clearly demonstrate that $P$. isidori and $G$. petersii can discriminate EOD waveforms between species, and even within species for $P$. isidori. The difference is perceived extremely fast. The discrimination can be associated with reinforcement, and thus evoke or inhibit a behavior, as in our test. The discriminated EOD of a dominant or submissive, stranger, male, or of some other kind of fish may therefore release a directed reaction by the receiver.

In our procedure the two pulse types were successively presented from the same electrodes which were located at a constant distance from the receiver's hiding place. The fact that discrimination was then observed in spite of a randomly variable amplitude shows that discrimination may be possible in natural conditions, when stimulus amplitude changes with varying positions of the fish.

The fish may, for instance, either compare the amplitude of two or several important frequencies of the spectrum content of the EOD, or the phase shift between these two frequencies (HEILIGENBERG \& ALTES 1978) as in gymnotiforms.

A discrimination mechanism involving the time lag between rapid voltage transients has been supported in mormyrids for Brienomyrus brachyistius "long triphasic" (HOPKINS \& BASS 1981). The EODs of these latter fishes are relatively long $(2000-5000 \mu \mathrm{s})$ and the salient temporal features were as different as 500 and $100 \mu \mathrm{s}$, respectively, in the two distinguished signals. In contrast, the EOD main phase duration of $P$. isidori is less than $1 / 10$ as long, with less than $50 \%$ difference between individuals. The mechanism postulated above involves the Knollenorgane, low threshold electroreceptors which give a fixed response regardless of the amplitude (or the shape) of the stimulus. From there on, a time lag of $10 \mu \mathrm{s}$ is not very likely to be encoded at the receptor level. Rather, the message (delay) from different Knollenorgane must be matched higher up in the central nervous system.

The distance to the electrodes and the amplitudes used $(10 \mathrm{mV} / \mathrm{cm}$ at the receiver) are still in accordance with a mechanism involving other, higher threshold receptors, the mormyromasts. The mormyromasts (BENNETT 1967, cited in SZABO \& FESSARD 1974; BELL 1986) consist of several receptor cells of two types, and code for the amplitude of electric pulses by a graded response (SzABO 
1974; BELL 1990 a, b, c). Different receptor cells tuned to different frequencies, or frequency ranges could generate specific combinations of responses already at the periphery. Such a mechanism may better explain the correlation between amplitude and locomotor response latency for fish Pi-5. However, Mormyromasts are broadly tuned, and they have also been considered responsible for the preferred latency response (BAUER \& KRAMER 1974; Russell et al. 1974), which was not observed in our recordings. It might be possible to make some inference about the receptor type if the voltage threshold for discrimination could be determined behaviorally, as in KNUDSEN (1974).

The EOD waveform can thus contribute to species- and social-recognition, together with other electrical and/or non-electrical cues (KRAMER 1978, 1979; Moller \& Serrier 1986; Bratton \& Kramer 1989). Eco-ethological data on Pollimyrus are too scanty to assess a precise role of intraspecific recognition. Its social structure observed in aquariums seems simple. Basically, bigger fish seem dominant, and mature males defend territories where they build nests. There seems to be no restrictive pair bond: males alone take care of the young. Males and females in captivity spontaneously change spawning partners (CRAWFORD et al. 1986; Kirschbaum 1987; Bratton \& Kramer 1989). In such context, individual recognition does not appear necessary.

Social recognition may be relevant in a crowded natural breeding area, where the EOD may function as a territorial marker for neighboring males, and indicate the arrival of newcomers, in the way that acoustical signals function in damselfish (MYrberg \& Riggio 1985; Myrberg et al. 1986). The pulse waveform parameters considered may, of course, play a role for sex recognition, but not an essential one as individuals of the "wrong" EOD waveform type have spawned in captivity (BRATTON \& Kramer 1989).

In fact, sexual signalling in mormyrids may also be mediated by the intervals separating EOD pulses. Sequences of inter-pulse intervals trigger differential spontaneous responses (KRAMER 1979; TEYsSEDRE \& SERRIER 1986), and depend partially on the sex in Pollimyrus (BratTon \& KRAmer 1989) and B. brachyistius (HOPKINS \& BASS 1981). Sequences of inter-pulse intervals may be adjusted by the signaller, together with acoustical and locomotor displays observed during courtship (Kirschbaum 1987; CrawFord et al. 1986; Bratton \& Kramer 1989).

The signalling value of the sequences of pulse intervals has been stressed over that of pulse waveform since changes in water quality (SERRIER \& GRAFF 1985; BRATTON \& KRAMER 1988) affect the EOD waveform in certain conditions. The EOD depends also on hormone level (Bass \& Hopkins 1983; Moller \& LANDSMAN 1987, 1988). The waveform may actually function as an indicator of internal state such as sexual maturation or stress.

\section{Acknowledgements}

This work was financed by the Deutsche Forschungsgemeinschaft (SFB4, Teilprojekt H1) to B. Kramer. B. O. BRATton provided the EODs used for stimulation. Thanks to P. LofTUS and T. BRENNEN who corrected the manuscript, and to Ethology's referees' helpful advices. G. von der EMDE friendly stood by for all kinds of effective support. 


\section{Literature Cited}

BASS, A. H. \& Hopkins, C. D. 1983: Hormonal control of sexual differentiation: changes in electric organ discharge waveform. Science 220, 971-974.

BAUER, R. \& KRAMER, B. 1974: Agonistic behaviour in mormyrid fish: latency-relationship between the electric discharges of Gnathonemus petersii and Mormyrus rume. Experientia 30, 51.

BELL, C. C. 1986: Electroreception in mormyrid fish. Central physiology. In: Electroreception. (Bullock, T. H. \& HeiligenberG, W., eds.) J. Wiley and Sons, New York, pp. 423-453.

- 1990a: Mormyromast electroreceptor organs and their efferent fibers in mormyrid fish: I. Morphology. J. Comp. Neurol. 286, 391-407.

- 1990 b: Mormyromast electroreceptor organs and their efferent fibers in mormyrid fish: II. Intra-axonal recordings show initial stages of central processing. J. Comp. Neurophysiol. 63, 303-318.

- - 1990c: Mormyromast electroreceptor organs and their efferent fibers in mormyrid fish: III. Physiological differences between two morphological types of fibers. J. Comp. Neurophysiol. 63, 319-332.

- -, MYers, J. P. \& RUSSELl, C. J. 1974: Electric organ discharge patterns during dominance related behavioral displays in Gnathonemus petersii (Mormyridae). J. Comp. Physiol. 92, $201-228$.

BennetT, M. V. L. 1971: Electroreception. In: Fish Physiology. Vol. 5. (Hoar, W. S. \& Randalt, D. J., eds.) Acad. Press, New York, pp. 493-574.

BRATTON, B. O. \& KRAMER, B. 1988: Intraspecific variability of the pulse-type discharges of the African electric fishes, Pollimyrus isidori and Petrocephalus bovei (Mormyridae, Teleostei), and their dependence on water conductivity. Exp. Biol. 47, 227-238.

- $\&-1989$ : Patterns of the electric organ discharge during courtship and spawning in the mormyrid fish Pollimyrus isidori. Behav. Ecol. Sociobiol. 24, 349-368.

CRAwFord, J. D., Hagedorn, M. \& Hopkins, C. D. 1986: Acoustic communication in an electric fish, Pollimyrus isidori (Mormyridae). J. Comp. Physiol. 159, 297-310.

GreenberG, L. H. 1975: Physics for Biology and Pre-med Students. W. B. Saunders Co., Philadelphia.

HeIligenberG, W. \& Altes, R. A. 1978: Phase sensitivity in electroreception. Science 199, $1001-1004$.

HOPKINS, C. D. 1972: Sex differences in electric signaling in an electric fish. Science 176, 1035-1037.

- 1981: On the diversity of electric signals in a community of mormyrid electric fish in West Africa. Amer. Zool. 21, 211-222.

- - \& BAss, A. H. 1981 : Temporal coding of species recognition signals in an electric fish. Science $212,85-87$.

KiRSCHBAUM, F. 1987: Reproduction and development of the weakly electric fish, Pollimyrus isidori (Mormyridae, Teleostei) in captivity. Env. Biol. Fishes 20, 11-31.

KNUDSEN, E. I. 1974: Behavioral thresholds to electric signals in high frequency electric fish. J. Comp. Physiol. 91, 333-353.

KRAMER, B. 1978: Spontaneous discharge rhythms and social signalling in the weakly electric fish Pollimyrus isidori (Cuvier et Valenciennes) (Mormyridae, Teleostei). Behav. Ecol. Sociobiol. 4, 61-74.

- - 1979: Electric and motor responses of the weakly electric fish Gnathonemus petersii (Mormyridae), to play-back of social signals. Behav. Ecol. Sociobiol. 6, 67-79.

- -, Kirschbaum, F. \& MARKL, H. 1981: Species specificity of electric organ discharge in a sympatric group of gymnotoid fish from Manaus (Amazonas). In: Advances in Physiological Sciences. Vol. 31 Sensory Physiology of Aquatic Vertebrates. (SzABO, T. \& CzEH, G., eds.) Pergamon Press, Oxford, pp. 195-220.

- - \& OTTO, B. 1988: Female discharges are more electrifying: spontaneous preference in the electric fish Eigenmannia (Gymnotiformes, Teleostei). Behav. Ecol. Sociobiol. 23, 55-60.

- - \& WeSTBY, G. W. M. 1985: No sex difference in the waveform of the pulse-type electric fish, Gnathonemus petersii (Mormyridae). Experientia 41, 1530-1531.

- — WEYMANN, D. 1987: A microprocessor system for the digital synthesis of pulsed and continuous discharges of electric fish (or animal vocalizations). Behav. Brain. Res. 23, $167-174$. 
- - \& ZUPANC, G. K. H. 1986: Conditioned discrimination of electric waves differing only in form and harmonic content in the electric fish, Eigenmannia. Naturwiss. 73, 679-681.

LANDSMAN, R. E. \& MOlleR, P. 1987: Stress obscures signalling of species identity in Gnatbonemus petersii (Mormyriformes). In: Proc. 3rd Int. Symp. on Reprod. Physiol. Fish. (IDLER, D. R., CRIM, L. W. \& Walsh, J. M., eds.) St. John, Newfoundland, p. 307.

- $-\&-1988$ : Testosterone changes the electric organ discharge and external morphology of the mormyrid fish, Gnathonemus petersii (Mormyriformes). Experientia 44, 900-903.

LISSMANN, H. W. 1958: On the function and evolution of electric organs in fish. J. Exp. Biol. 35, $156-191$.

- 1961: Ecological studies on gymnotids. In: Bioelectrogenesis. (CHAGAS, C., ed.) Elsevier, New York, pp. 215-223.

Moller, P. \& Serrier, J. 1986: Species recognition in mormyrid electric fish. Anim. Behav. 34, $333-339$.

MyrberG, A. A., Jr., Mohler, M. \& Catala, J. D. 1986: Sound production by males of a coral reef fish (Pomacentrus partitus): its significance to females. Anim. Behav. 34, 913-923.

- \& RIGgIO, J. R. 1985: Acoustically mediated individual recognition by a coral reef fish (Pomacentrus partitus). Anim. Behav, 33, 411-416.

Russell, C. J., Myers, J. P. \& Bell, C. C. 1974: The echo response in Gnathonemus petersii (Mormyridae). J. Comp. Physiol. 92, 181-200.

SERrier, J. \& GRAFF, C. 1985: Effet de la température sur la décharge électrique des Mormyres. J. Physiol. Paris 80, 131.

SCHLuger, J. H. \& HOPKINS, C. D. 1987: Electric fish approach stationary signal sources by following electric current lines. J. Exp. Biol. 130, 359-367.

SIEGEL, S. 1956: Non-parametric Statistics for the Behavioral Sciences. McGraw Hill, New York.

SZABO, T. 1974: Anatomy of the specialized lateral line organs of electroreception. In: Handbook of Sensory Physiology. Vol. 3 Electroreceptors and Other Specialized Receptors in Lower Vertebrates. (Fessard, A., ed.) Springer Verlag, Berlin, pp. 13-58.

- — F FESARD, A. 1974: Physiology of electroreceptors. In: Handbook of Sensory Physiology. Vol. 3 Electroreceptors and Other Specialized Receptors in Lower Vertebrates. (FESSARD, A., ed.) Springer Verlag, Berlin, pp. 60-121.

TEYSSEDRE, C. \& SERRIER, J. 1986: Temporal spacing of signals in communication, studied in weakly electric fish (Teleostei, Pisces). Behav. Proc. 12, 77-98.

Westby, G. W. M. \& Kirschbaum, F. 1982: Sex differences in the waveform of the pulse-type electric fish, Pollimyrus isidori (Mormyridae). J. Comp. Physiol. 145, 399-404.

Received: April 24, 1991

Accepted: December 11, 1991 (H.-U. Reyer) 